\title{
Scalping techniques in geomechanical characterization of coarse granular materials
}

\section{Técnicas de corte para la caracterización geomecánica de materiales granulares gruesos}

\section{Leonardo Dorador ${ }^{1}$ and Felipe A. Villalobos ${ }^{2}$}

\author{
${ }^{1}$ EGSciences SpA, Santiago, Chile, info@egsciences.com
}

${ }^{2}$ Department of Civil Engineering, Faculty of Engineering, Universidad Católica de la Santísima Concepción, Concepción, Chile, avillalobos@ucsc.cl (Orcid: 0000-0002-5419-3958)

The study of materials with large particle size has been a great challenge in geotechnical engineering. Despite the current work around the world using coarse-grained materials CGM in rockfill dams and mining waste rock dumps, for instance the geotechnical characterization of these materials is still an important issue in geotechnical engineering practice which deserve more research. There are standards covering CGM in a few particular applications and scaling methods have been proposed to deal with large particle sizes. However, scaling methods are appropriate only under certain conditions. The scalping techniques consist in a simple approach for the geotechnical characterization of CGM. In this article, the scalping techniques analysed are divided in: the scalping method, the matrix method and the scalping/replacement, which are studied in detail in terms of its effectiveness, focusing on the geomechanical characterization of CGM. As a main conclusion, these three techniques are limited in its use under small scalping ratios $(3<r<8)$ which is the ratio of maximum particle size of both original and scalped gradation. Finally, recommendations for the use of percentages and ratio of scalping are provided.

Keywords: coarse granular materials, scalping method, geotechnical characterization, size-scaling, shear strength
El estudio de materiales granulares gruesos ha sido un gran desafio para la ingeniería geotécnica. A pesar del uso intensivo de materiales granulares gruesos $M G G$ alrededor del mundo, por ejemplo en presas de enrocado y lastres de mina, la caracterización geotécnica de estos materiales sigue siendo un tema importante en la ingeniería práctica que requiere más investigación. Existen normas sobre $M G G$ para aplicaciones muy particulares y se han propuesto métodos de escalamiento de tamaño. Sin embargo, los métodos de escalamiento de tamaño son adecuados solo bajo ciertas condiciones. En este artículo se analizan las técnicas de corte, las cuales permiten realizar una caracterización geotécnica de forma simple. Las técnicas de corte se puede dividir en: el método de corte, método de matriz y corte/reemplazo, los cuales son analizados en detalle en términos de su efectividad para la caracterización geomecánica de MGG. Como conclusión principal, estas tres técnicas están limitadas en su uso bajo razones de corte pequeñas $(3<r<8)$, que es la razón del tamaño máximo de partícula de la gradación original y la muestra cortada. Finalmente, se proporcionan recomendaciones para el uso de porcentajes y razones de corte.

Palabras clave: materiales granulares gruesos, método de corte, caracterización geotécnica, escalamiento de tamaño, resistencia al corte

\section{Introduction}

The geotechnical characterization of very coarse-grained materials (CGM) such as coarse-grained soils, rockfills, mine waste rock and related materials is one of the key themes in the practice of geotechnical engineering despite being least studied and developed. Although there are some geotechnical standards related to CGM (e.g. ASTM
D4718, 2015; ASTM D5030, 2013) there is not a standard for scaling large particle sizes, which is a critical step in advanced stage engineering such as the detailed design of large structures containing this type of materials (e.g. rockfill dams, mining waste rock dumps). Applications in Geotechnical Engineering cover materials from large dams and embankments in civil engineering; crushed ballast in 
pavement and railway engineering; rockfill, waste rock, stockpiles and dump leached materials in surface mining, as well as broken ore materials in underground mining are some examples of Coarse Granular Materials (CGM), which can be defined as granular materials containing particles larger than $75 \mathrm{~mm}$. Two main types of CGM have been defined, namely sedimentary CGM and rockpiles (Dorador et al., 2018; Dorador and Villalobos, 2020). The first group refers to soil-rock mixtures (fluvial and alluvial materials, glacial till) affected by external geological processes, while rockpile materials refer to ensembles of rock particles, which are not affected significantly by geological erosion processes (quarry rockfill, mine waste rock, heap leached materials).

A key property of CGM to be considered in the scalping techniques is that particles of a CGM can change their physical characteristics with size. A qualitative description of particle strength as a function of CGM particle size have been proposed by Dorador and Villalobos (2020), where four categories are defined. In the first category, strength and stiffness do not change with the average particle size $D_{50}$. Alluvial and fluvial materials can be considered in category 1 . In the second category strength and stiffness do reduce with $D_{50}$ due to rock fracturing. Most of the rockpiles (quarry rockfill, mine waste rock and broken ore materials in underground mining) are represented by category 2 . In the third category, strength and stiffness reduce with $D_{50}$ on one side for sand particle sizes owing to mineralogical effects and on the other side for much larger particle sizes caused by rock fracturing, while for particles in between there is no change. Category 3 can be applied to heap leach materials and rockpiles affected by segregation of smaller and weaker particles. Finally, in category 4 strength and stiffness increase with $D_{50}$, which could be a mixture scenario for rockpiles with smaller but weaker particles and larger but stronger particles such as the case of contaminated rockfill materials. Other properties such as particle shape and roughness can also change with size and it should be considered when conducting a geotechnical characterization of CGM.

For practical purposes, it is considered that a scalping technique is effective in the representation of the CGM if the scalped material does not have a difference greater than 3 degrees of internal friction angle. A similar criterion can be adopted when analyzing the effectiveness of the parallel gradation method, also known as homothetic grain size distribution (e.g. Dorador and Villalobos, 2020; Dorador, 2010, 2018; De la Hoz, 2007).

A comprehensive evaluation of CGM geotechnical parameters is critical for detailed engineering stages in civil and mining projects. Numerous embankment and tailings dams around the world have been reported higher than 200 $\mathrm{m}$, while waste rock dumps could reach heights of up to $500 \mathrm{~m}$ (e.g. Valenzuela et al., 2008; Hawley and Cunning, 2017). Unfortunately, the evaluation of the geotechnical properties of this type of materials is an arduous task due to the high cost, lack of equipment, time and availability for testing large samples of material (e.g. Ovalle et al., 2020). Moreover, there are major difficulties in terms of sizescaling techniques to reproduce geotechnical properties of large samples to smaller particles, because laboratory tests are commonly performed on small specimens due to equipment size limitations. Currently, there are several methods reported in the literature for scaling the particle size of CGM, but each has limitations on its use.

Among these methods, the Parallel Gradation Method (PGM) is the most reliable method for scaling the geomechanical properties of coarse-grained materials, although it is limited on its use (Dorador et al., 2018; Dorador and Villalobos, 2020). This leads to the consideration of additional scaling procedures for geotechnical characterization of CGM. In this line, Scalping Techniques appear as an attractive alternative, which relies on removing the largest particles of a CGM sample, in order to use the scalped (or finer) samples for laboratory testing. In addition, this technique is preferred by geotechnical companies who provide laboratory testing services (Dorador, 2018).

Thus, the analysis of the scalping techniques is addressed in terms of assessing the mechanical properties of CGM, specifically under the maximum internal friction angle. The scalping techniques discussed in detail through this work are: a) the scalping method, b) the matrix method and c) the scalping and replacement method.

\section{The scalping method}

The scalping method, also referred to as clipping by Seif El Dine et al. (2010) and cut method by Bard et 
al. (2012), consists of removing the oversize particles with the finer material being tested in a conventional shear testing device, i.e. direct shear or triaxial shear, which is a common practice in geotechnical testing laboratories (Dorador, 2018). The idea of scalping on coarse granular materials was probably first reported by Zeller and Wullimann (1957). Since then, many authors have analyzed and applied this method (e.g. Leslie, 1963; Donaghe and Cohen, 1978; Al-Hussaini, 1983; Simoni and Houlsby, 2006; De la Hoz, 2007; Bareither et al., 2008; Flora and Modoni, 1997). After conducting the scalping procedure, the final particle size distribution PSD is finer and more uniform, which directly affects the estimation of shear strength and deformation modulus of the coarse material. Consequently, several authors, as shown in Table 1 , have recommended a maximum percentage of scalping in order to reproduce the mechanical properties of CGM based on smaller (scalped) samples. Nevertheless, some authors have said that scalping is not a problem in terms of evaluating the shear strength of large samples (McCarter, 1985).

Table 1: Maximum percentage of scalping recommended by different authors

\begin{tabular}{|l|c|l|}
\hline Authors & $\begin{array}{c}\text { Scalping \% } \\
\text { recommended }\end{array}$ & \multicolumn{1}{|c|}{ Based on } \\
\hline $\begin{array}{l}\text { Donaghe and } \\
\text { Cohen (1978) }\end{array}$ & 10 & $\begin{array}{l}\text { CIU triaxial tests using the } \\
\text { scalping and replacement method }\end{array}$ \\
\hline $\begin{array}{l}\text { Fragazsy et al. } \\
(1992)\end{array}$ & 30 & $\begin{array}{l}\text { CID and CIU triaxial tests using } \\
\text { the matrix method }\end{array}$ \\
\hline Jernigan (1998) & 25 & $\begin{array}{l}\text { CID triaxial tests using the matrix } \\
\text { method }\end{array}$ \\
\hline $\begin{array}{l}\text { De la Hoz } \\
(2007)\end{array}$ & 20 & $\begin{array}{l}\text { CID triaxial tests using the } \\
\text { scalping method }\end{array}$ \\
\hline $\begin{array}{l}\text { Bareither } \text { et al. } \\
(2008)\end{array}$ & 30 & $\begin{array}{l}\text { direct shear tests using the } \\
\text { scalping method }\end{array}$ \\
\hline
\end{tabular}

The ratio of scalping $r$ is defined as:

$r=\frac{D_{100}(\text { original PSD })}{D_{100}(\text { scalped PSD })}$

where $D_{100}$ is the largest particle size of the material. Figures $1 \mathrm{a}$ and $1 \mathrm{~b}$ show graphically the percentage of scalping.

To scalp a large particle from a matrix of smaller particles is still a topic under study. According to this, Lambe and Whitman (1969) have stated that:
In many soils, a few particles of relatively large size make up a large fraction of total weight of the soil. If these particles are numerous enough so that they interlock with each other, it is important that these large particles be present in the test specimen. However, if these larger particles are just embedded into a matrix of much smaller particles so that the shearing takes place through the matrix, then the large particles can be safely omitted from the specimen. Unfortunately, the profession is still lacking definitive guidelines as to what constitutes a satisfactory test upon a gravelly soil.

In addition, McLemore et al. (2009) indicated that although the scalping technique has been a center of discussion, there is no common agreement on the effect of scalping on the shear strength of soils. Hereafter the most significant experimental studies are discussed.
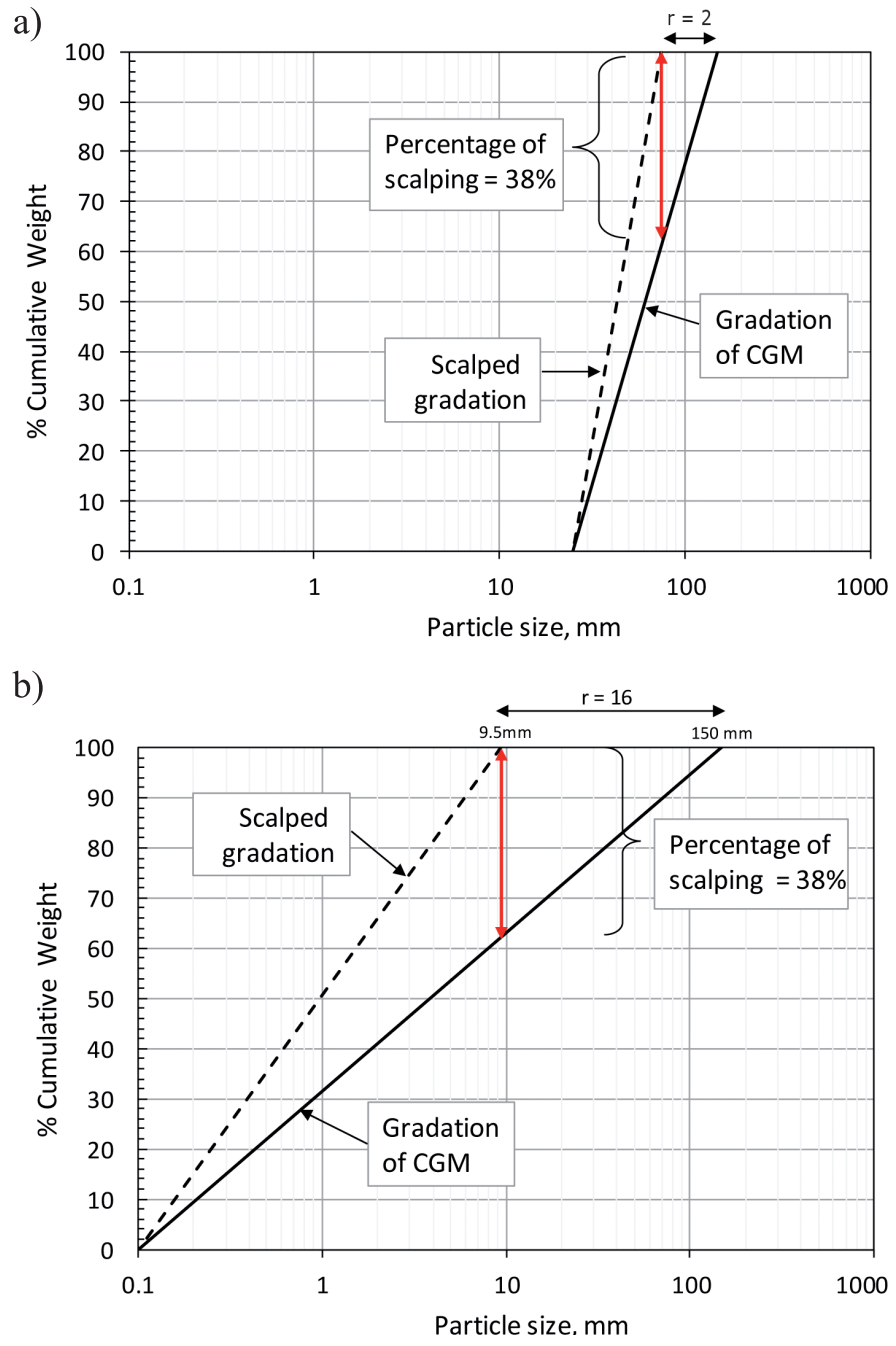

Figure 1: Comparison of scalping for the same percentage of scalping and different ratio of scalping $r$ for two gradations: a) uniform and b) well graded (not uniform) 
Leslie (1963) reported results from alluvial soils with subrounded to subangular particles. Specifically, four PSD depicted in Figure 2a were analyzed, with a maximum ratio of scalping $r$ of 8. Also, the author indicated that each specimen was compacted by vibration to attain the maximum density. The results indicated that the scalping affected in less than 3 degrees the angle of internal friction between the original and scalped gradations (Figure $2 b$ ).

a)

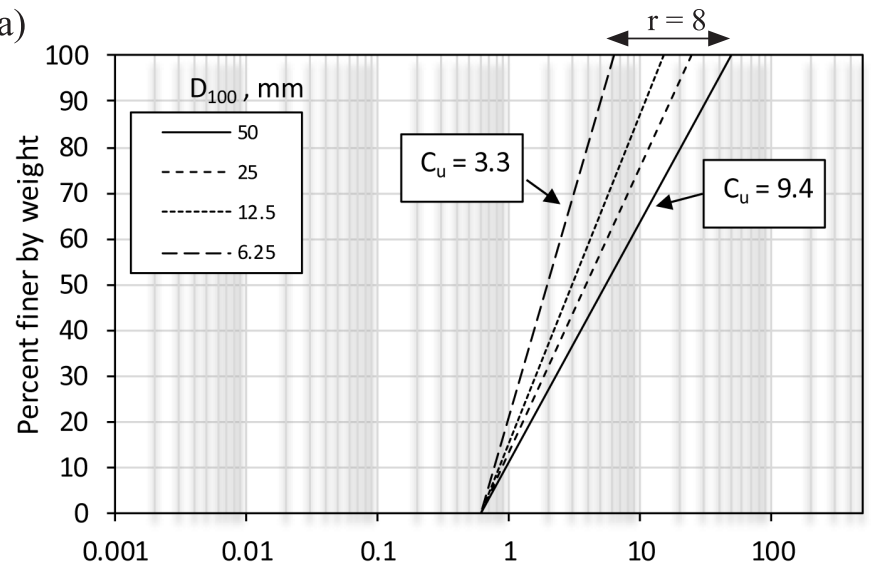

b)

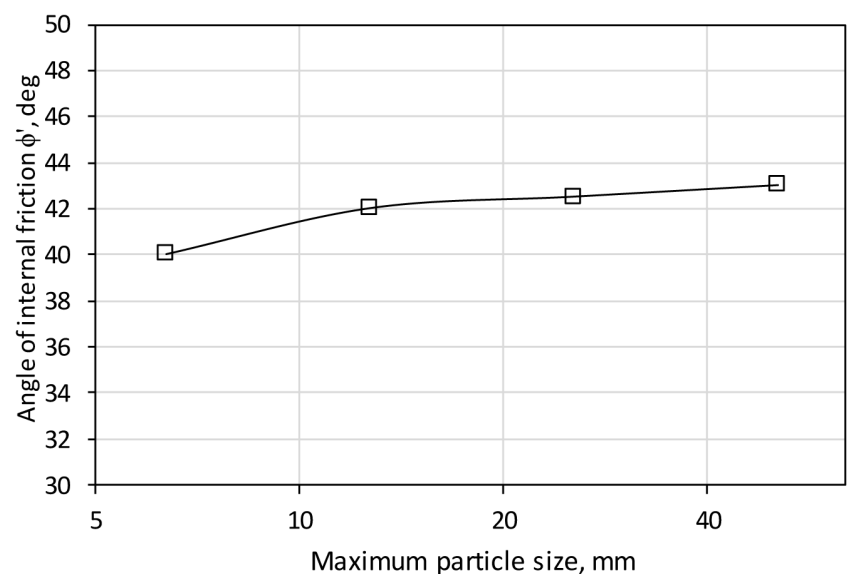

Figure 2: a) PSDs tested and b) internal friction angle versus maximum particle size (Leslie, 1963)

Considering a different material and gradations as shown in Figures 3a and 3b, Donaghe and Cohen (1978) found an increase in the friction angle $\phi$ ' when increasing the particle sizes up to 5 degrees for $r=12$, and 3 degrees for $r=6$.

Al-Hussaini (1983) reported results from a triaxial testing programme on a crushed basalt material. The original and scalped PSD are shown in Figure 4a including a maximum scalping of $r=12$. The testing programme included specimens with a relative density of 75 and $100 \%$. Internal friction angles $\phi$ ' for a relative density RD of $75 \%$,
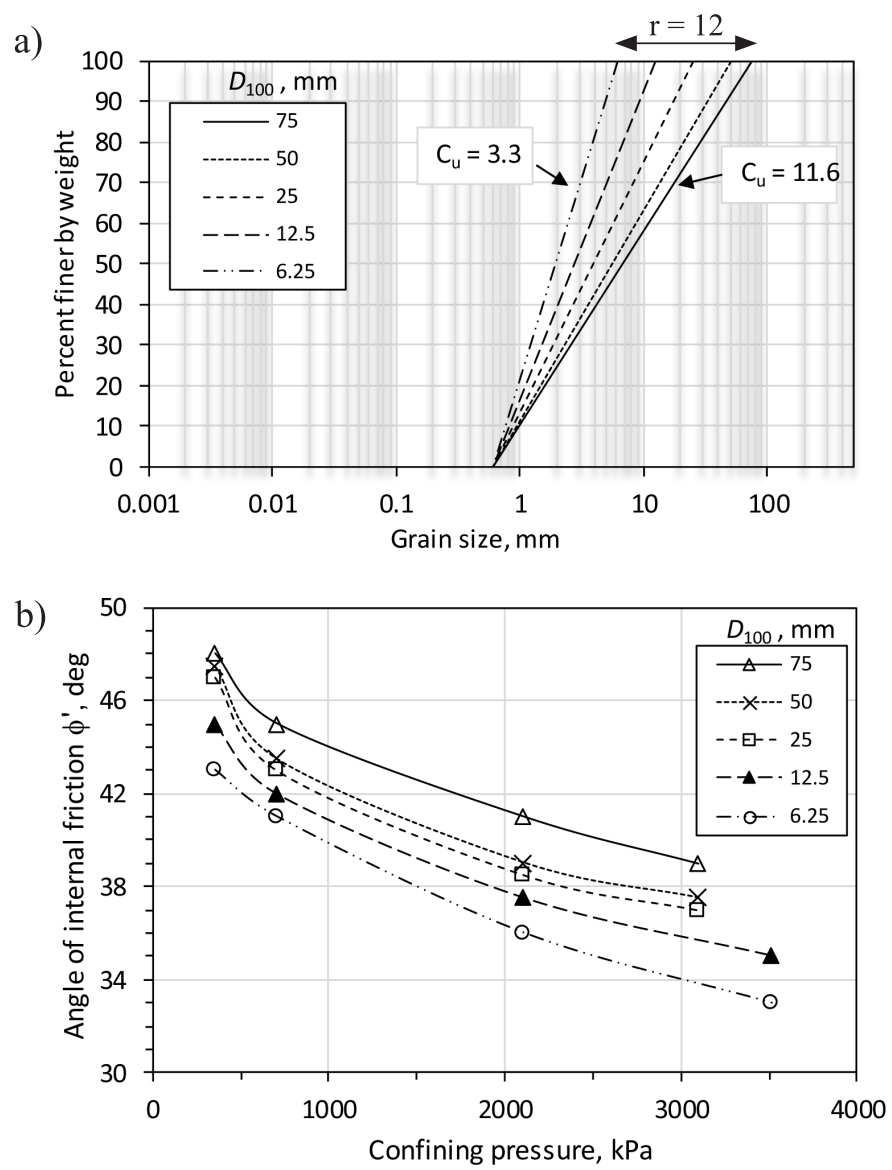

Figure 3: a) PSDs tested and b) internal friction angle versus confining pressure and maximum particle size (Donaghe and Cohen, 1978)

between confining pressures of $\sigma_{\mathrm{c}}=400 \mathrm{kPa}$ and $3000 \mathrm{kPa}$, are presented in Figure $4 \mathrm{~b}$. These results agree with the findings by Donaghe and Cohen (1978) with an increase of up to 7 degrees of $\phi$ ' for $r=12$, and 3 degrees for $r=6$.

De la Hoz (2007) also studied the scalping method based on triaxial compression tests using a fluvial gravel under a relative density RD of 70\%. De la Hoz (2007) suggested to scalp up to $20 \%$ to reproduce the shear strength parameters of CGM when the scalping method is applied. Figures 5a and $5 \mathrm{~b}$ present gradations and internal friction angles, respectively. It is interesting to note that the ratio of scalping used in this investigation was 2.6, and gradations up to $80 \%$ of scalping resulted in a difference of internal friction angle lower than 3 degrees. As it will be explained later, this large amount of scalping is explained by the ratio of scalping employed.

Continuing the research by De la Hoz (2007), Dorador (2010) analyzed the scalping method using a fluvial gravel with gradations and internal friction angles as shown in 
a)

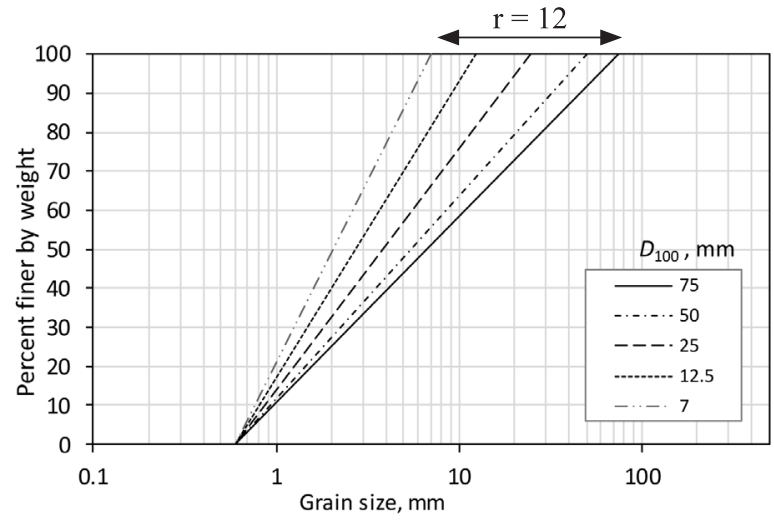

b)

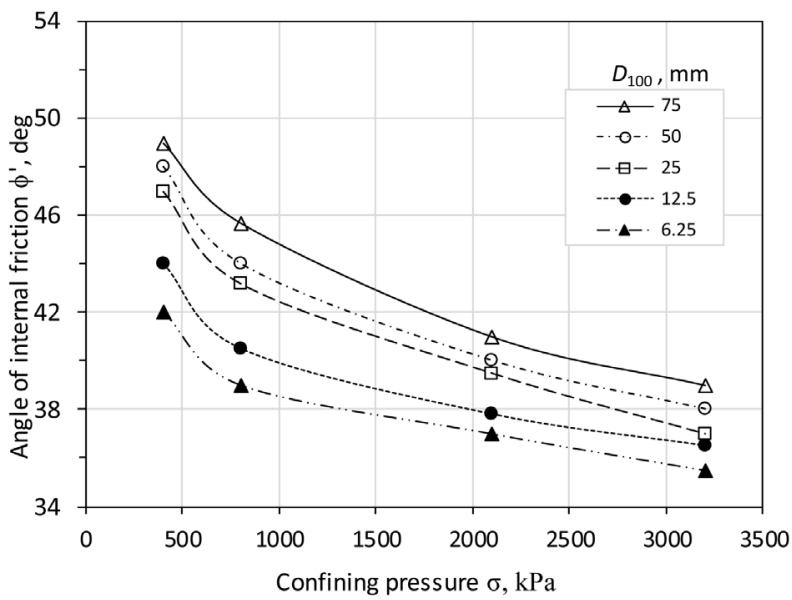

Figure 4: a) PSDs tested and b) internal friction angle versus confining pressure and maximum particle size for tests under RD $=75 \%$ (Al-Hussaini, 1983)
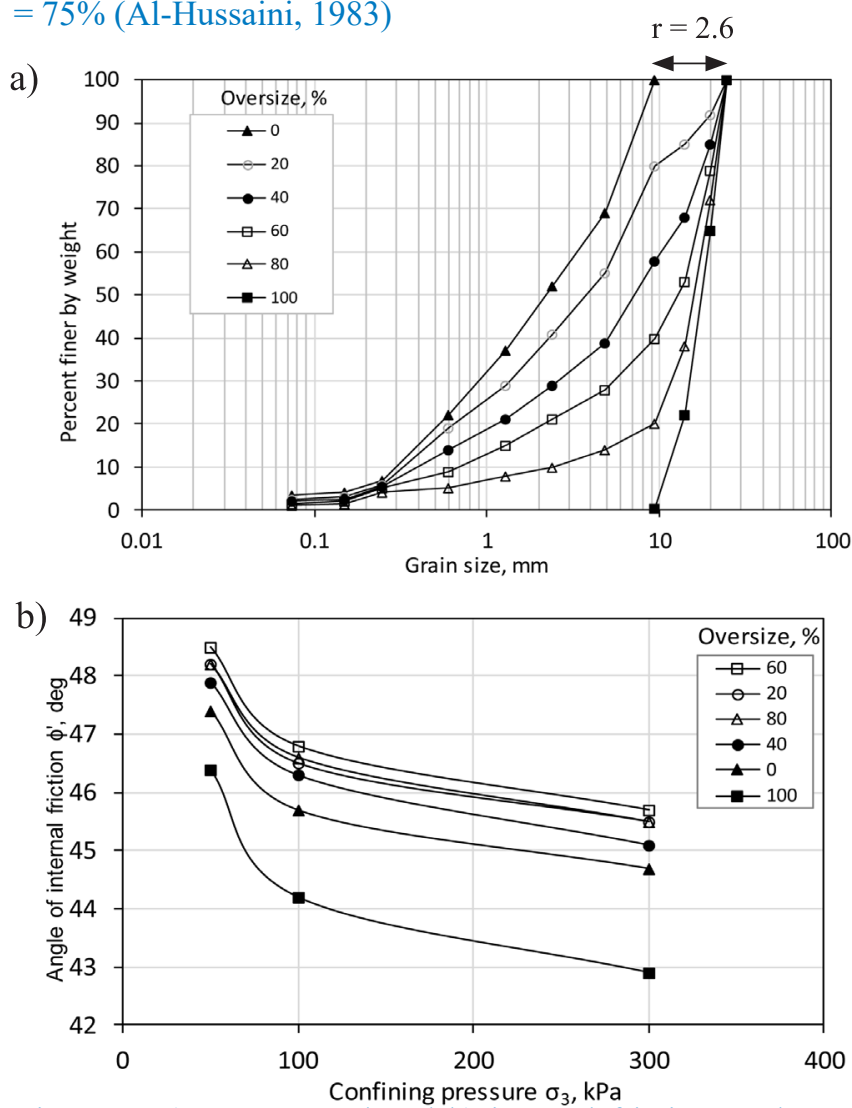

Figure 5: a) PSDs tested and b) internal friction angle versus confining pressure and oversize (De la Hoz, 2007)
Figures $6 \mathrm{a}$ and $6 \mathrm{~b}$. Using a scalping ratio of 5.3, a maximum scalping percentage of $35 \%$ was obtained.

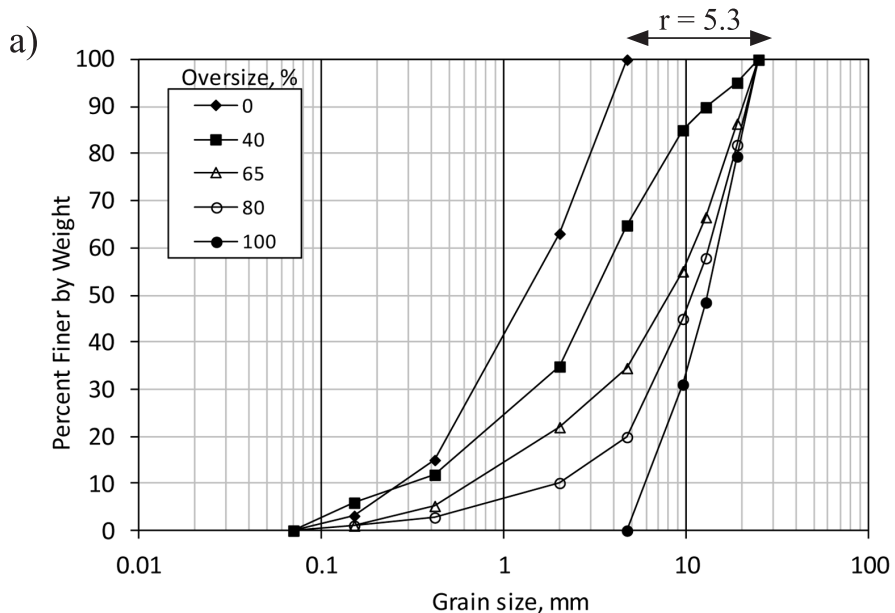

b)

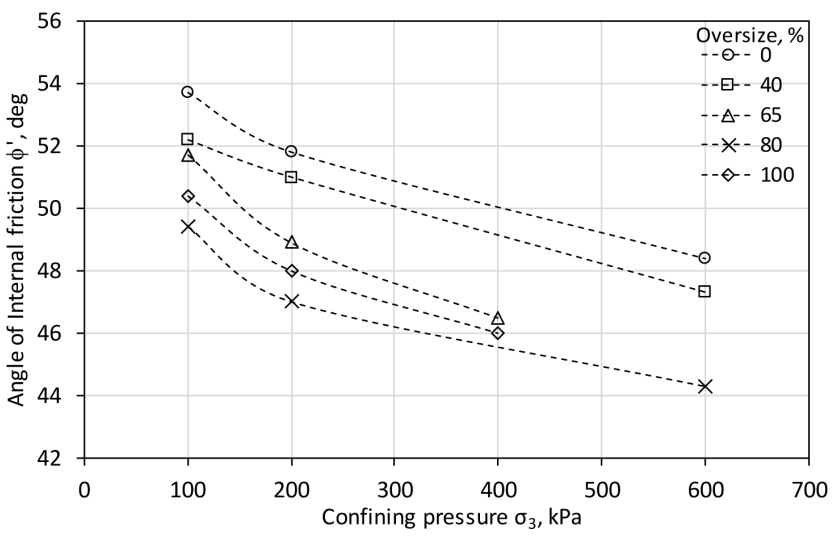

Figure 6: a) PSDs tested and b) internal friction angle versus confining pressure and oversize (Dorador, 2010)

According to the previous results, these authors have recommended that the percentage of scalping should be up to $30 \%$. However, as it will be discussed later, a percentage of scalping is not an optimal way to define the amount of scalping, because it depends on the particle size distribution of the CGM. As shown in Figures 1a and 1b, a uniform and well graded (not uniform) gradations can have the same scalping value of $38 \%$ but under a very different ratios of scalping. In addition, the use of this method will also depend on the engineering stage of the laboratory tests. For example, a difference of 3 degrees of internal friction angle can be important in a detailed engineering project, but perhaps not in a conceptual or feasibility stage project.

\section{The matrix method}

The second method analysed in this paper is the matrix method, initially proposed by Siddiqi (1984) and continued by Su (1989), Fragaszy et al. (1990, 1992), Bolton et al. 
(1991) and Jernigan (1998). This method relies on a solid background which considers that the oversize particle floats into a matrix of fine particles when compression and shear stresses are applied on the material as depicted in Figure 7a. Intuitively, the finer the matrix, the more effective the method would be as the shear band would be thinner and then, oversize particles would not participate in shear band formations. Thus, soil-rock mixtures (alluvial and fluvial materials, glacial till) which could contain significant fines contents are better candidates for use. The other case shown in Figure 7b, is when oversized particles are in contact with each other, which is also referred to as non-floating state.
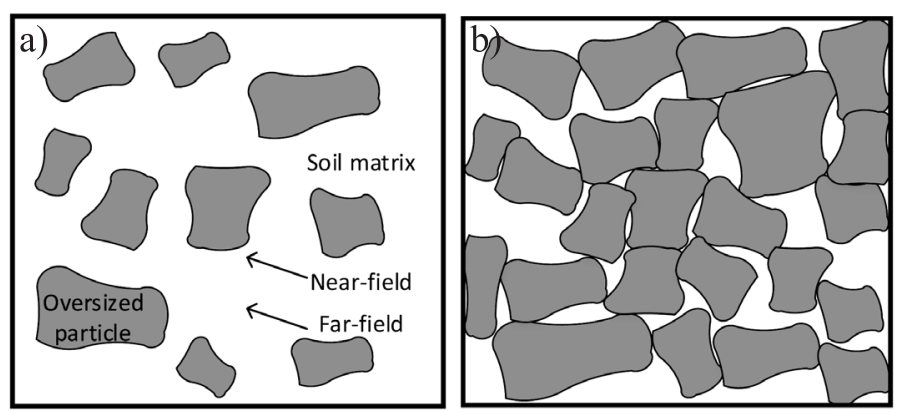

Figure 7: Matrix method with oversize particles: a) floating and b) in contact

Siddiqi (1984) introduced the matrix method, which is based on the hypothesis that in a granular material containing large and small particles, large particles will float into a matrix of small particles, and therefore, the latter will control the shear strength of the granular material. Siddiqi (1984) studied experimentally the effectiveness of this method in terms of static undrained triaxial tests and was able to corroborate the matrix method using a material from Lake Valley Dam in California, USA, for a specific gradation type shown in Figure 8a. The main concern of the results is that the ratio between the maximum particle size of the prototype and model gradation was only $r=4$, which is limited in use, regarding typical particle sizes of CGM obtained in practice. Figure $8 \mathrm{~b}$ presents two sets of tests, the former with $305 \mathrm{~mm}$ diameter (prototype) and the latter with $71 \mathrm{~mm}$ diameter (soil matrix), both with comparable relative density on specimens. The former resulted in lower maximum shear strength than the latter. Thus, the study recommended a density to be calculated as the average of the prototype relative density and the average density of the soil matrix. This issue motivated $\mathrm{Su}$
(1989) to propose a methodology to evaluate the far field density (soil matrix far from oversized particles).

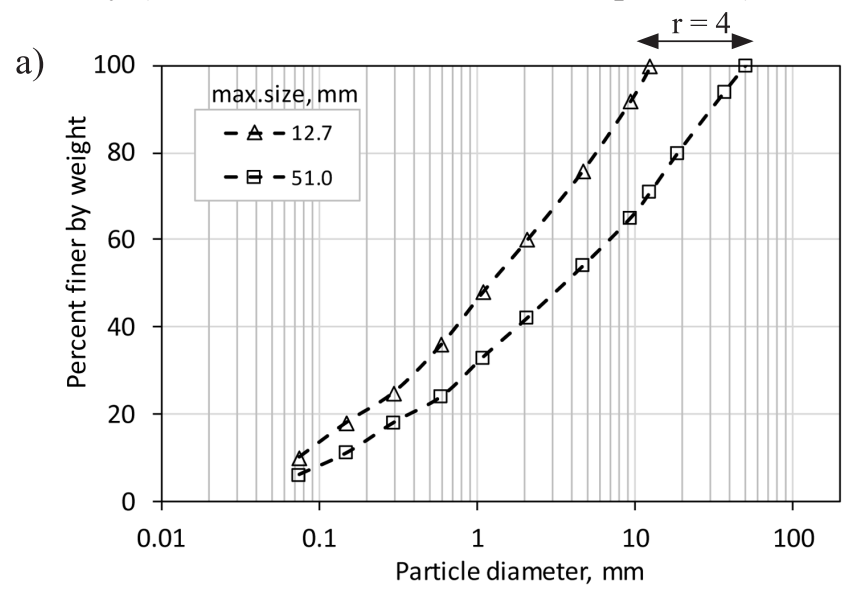

b)

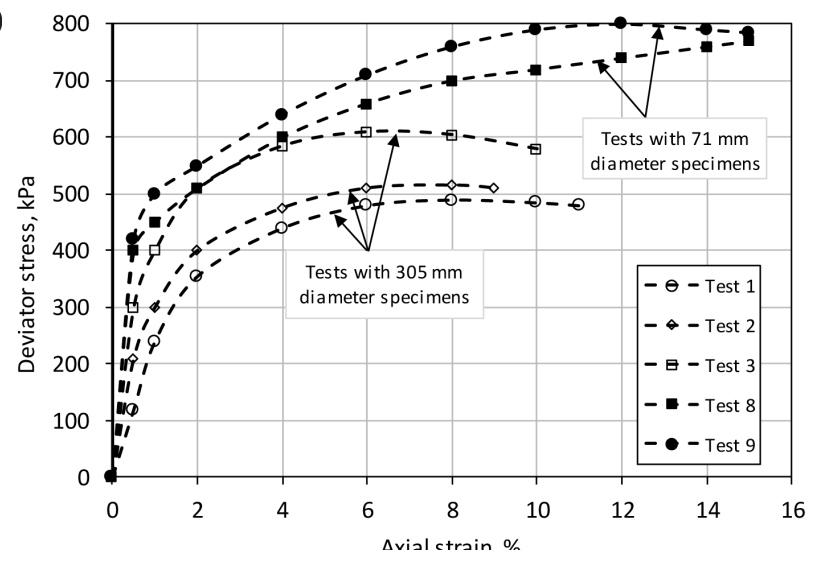

Figure 8: Lake Valley Dam material: a) PSDs tested and b) deviator stress versus axial strain and specimen diameter (Siddiqi, 1984)

$\mathrm{Su}$ (1989) extended the experimental work carried out by Siddiqi (1984), conducting static drained triaxial tests, as well as undrained triaxial tests. The matrix method was corroborated for triaxial CID tests. However, as depicted in Figures 9a and 9b, the scalping ratio was lower than that used by Siddiqi (1984), reaching only $r=2$. The works by Siddiqi (1984) and Su (1989) demonstrating the effectiveness of the matrix method were confirmed by Fragaszy et al. (1990, 1992).

Bolton et al. (1991) also used the matrix model to evaluate the shear strength of sandy soils with some percentage of gravel sizes as oversize material ( 15 and $30 \%$ of oversize). Regarding the two type of materials tested (Fill A \& B and Fill C \& D), they found differences between 1.5 and 3 degrees from the matrix soil material to the prototype under comparable relative density on specimens (Figures 10 and 11). The interesting point is that Bolton et al. (1991) 
a)

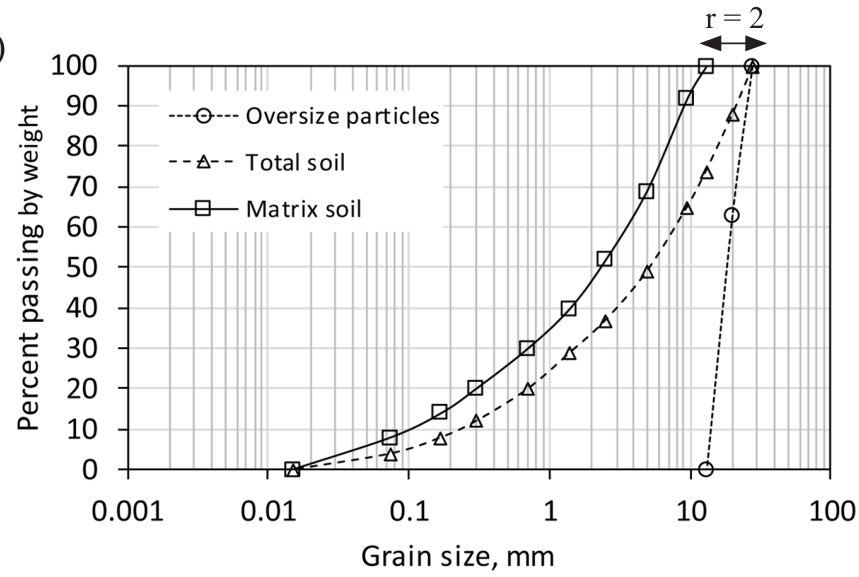

b)

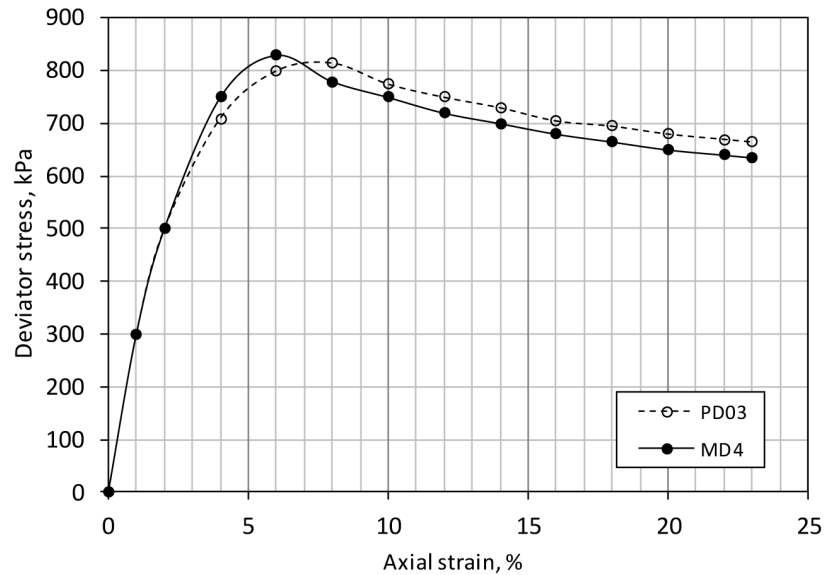

Figure 9: Lake Valley Dam material: a) PSDs tested and b) deviator stress versus axial strain, where PD03: $\mathrm{RD}=47.1 \%$, density $\rho=2.04 \mathrm{Mg} / \mathrm{m}^{3}$ and specimen diameter $D=152 \mathrm{~mm}$ and for MD4: $\mathrm{RD}=40.5 \%, \rho=1.92 \mathrm{Mg} / \mathrm{m}^{3}$ and $D=71 \mathrm{~mm}(\mathrm{Su}$, 1989)

indicated that oversize material could act as a reinforcement under the shear strain developed during testing.

Jernigan (1998) conducted triaxial compression CID tests, similar to the tests carried out by $\mathrm{Su}$ (1989). As presented in Figure 12, Jernigan (1998) conducted tests on a scalping of up to $30 \%$ for reproducing the mechanical properties of both original and model gradation, under a ratio of scalping of 7.9. In addition, Jernigan (1998) stated that the presence of oversized particles changes the shear strength characteristics of a soil, adding that this change depends upon the shape, surface texture, and angularity of the oversized particles. Based on experimental results, the presence of small amounts of oversized materials does not affect the peak shear strength of the soil as compared to the strength of the matrix material. However, the increase in the amount of oversized materials may reach a point where the peak shear strength rises rapidly once the matrix material strength is surpassed. a)

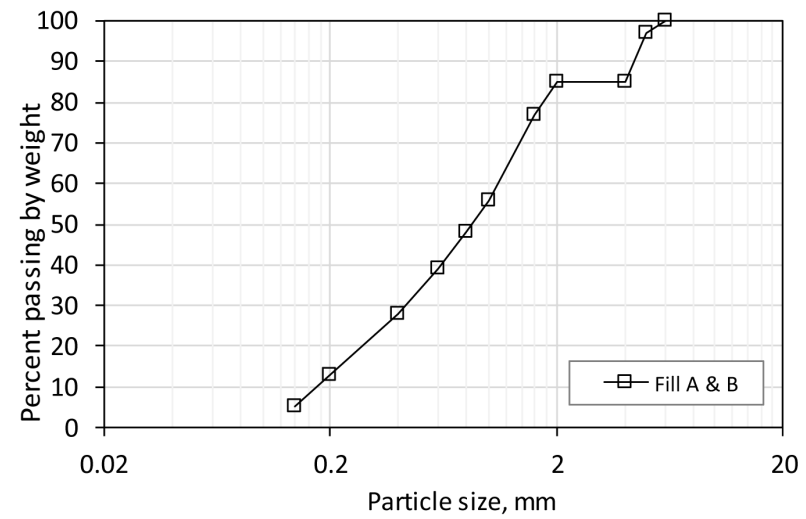

b)

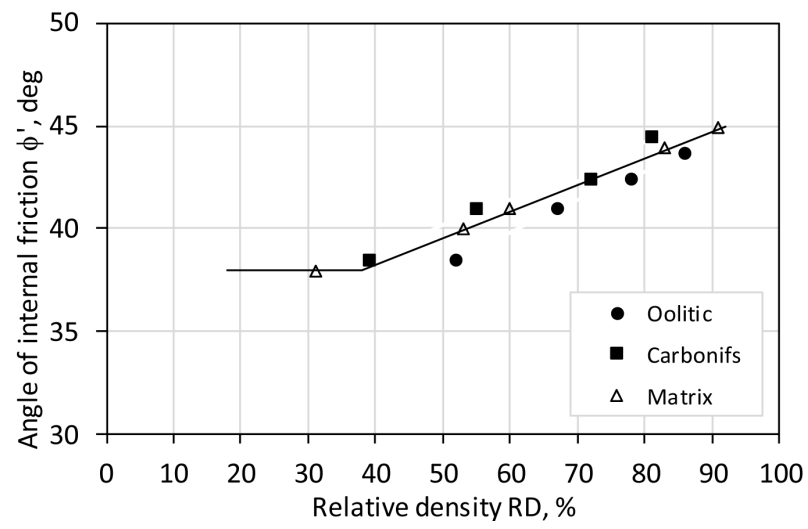

Figure 10: a) PSD tested and b) internal friction angle versus relative density for Fill A \& B (Bolton et al., 1991)

a)

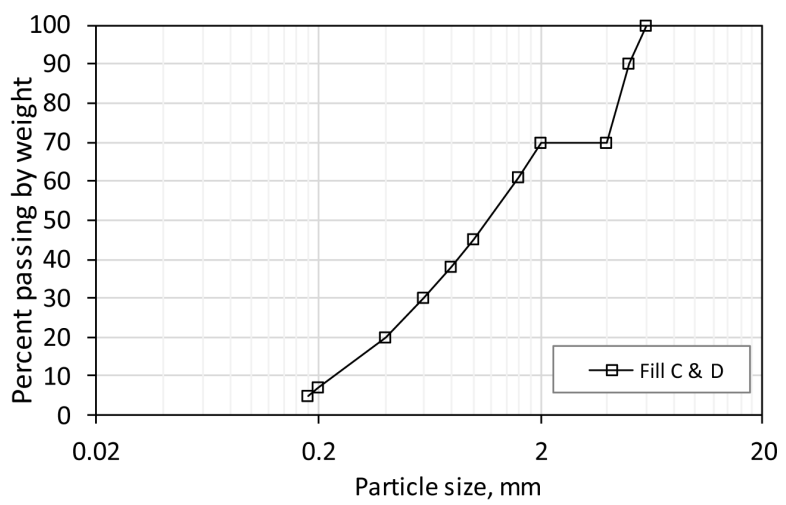

b)

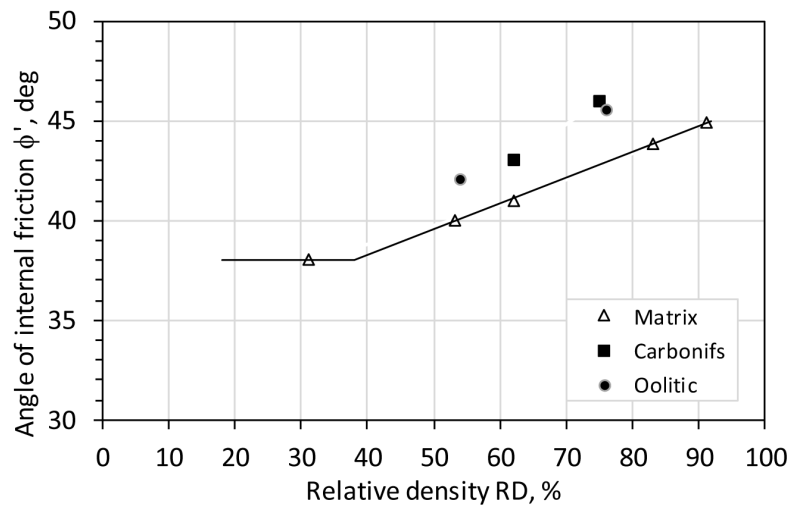

Figure 11: a) PSD tested and b) internal friction angle versus relative density for Fill C \& D (Bolton et al., 1991) 
a)

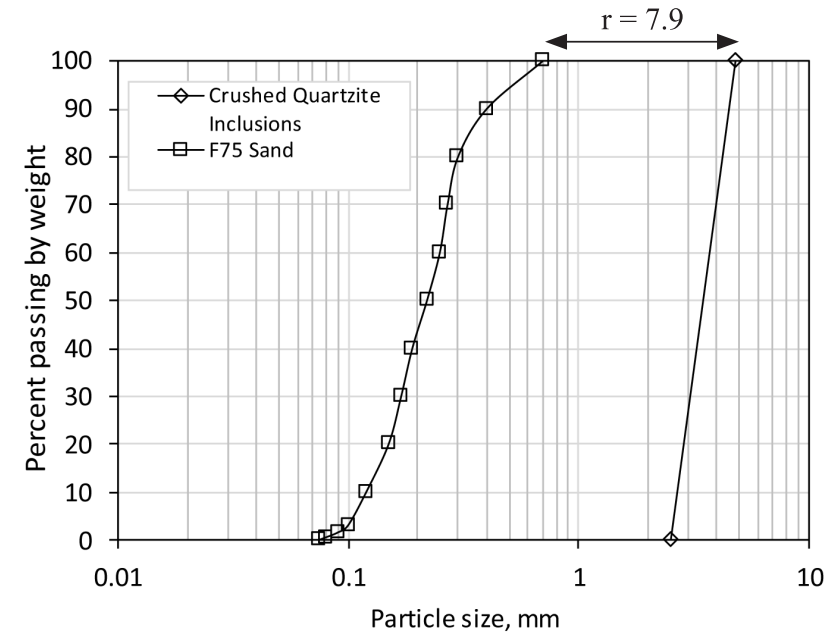

b)

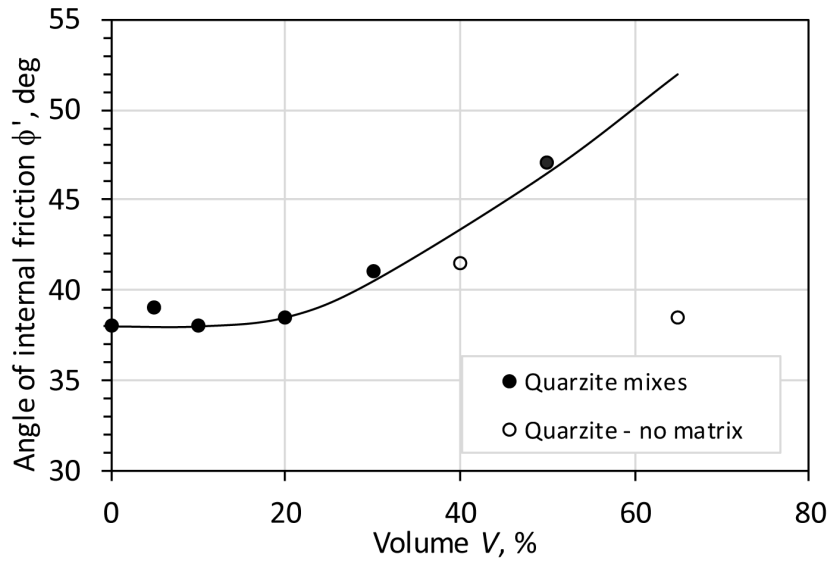

Figure 12: a) PSDs tested and b) internal friction angle results for Quartzite material (Jernigan, 1998)

The matrix method needs some improvements for rough and elongated large particle (Fragaszy et al., 1992; Bolton et al., 1991; Jernigan, 1998). The experiments by Siddiqi (1984) and Su (1989) considered small ratio of scalping (up to 6), which are not representatives of typical particle size distributions of CGM. Finally, the matrix method is ideal for samples with fines content higher than $10 \%$ and gap graded gradations, where oversize and soil matrix can be clearly defined, in other words, larger particle in comparison to small particles.

\section{The scalping and replacement method}

The scalping and replacement method was presented by Donaghe and Townsend $(1973,1976)$, and it was focused on the evaluation of compaction characteristics of earthfills. Later on Donaghe and Torrey (1979) extended this method to evaluate mechanical properties. The method aims in scalping an original gradation but keeping the same sample density of both original and scalped gradations.
As the scalped gradation is finer, the minimum and maximum density of a scalped gradation are lower than the original. As keeping the same density on both gradations, the relative density $\mathrm{RD}$ on scalped gradation is higher, which should generate different shear strength and compressibility results. In addition, the experiments published by Donaghe and Torrey $(1979,1985)$ were conducted on samples with more than $10 \%$ of fines content and under undrained conditions.

It is important to highlight the work by $\mathrm{Su}$ (1989), although limited to a few laboratory tests to study the effectiveness of this method, the triaxial tests were carried out under drained conditions based on gradations shown in Figure 13a. The results depicted in Figure 13b were inconclusive because of the large scatter of shear strength between the original $152 \mathrm{~mm}$ specimen diameter and scalped $71 \mathrm{~mm}$ specimen diameter gradations.

a)

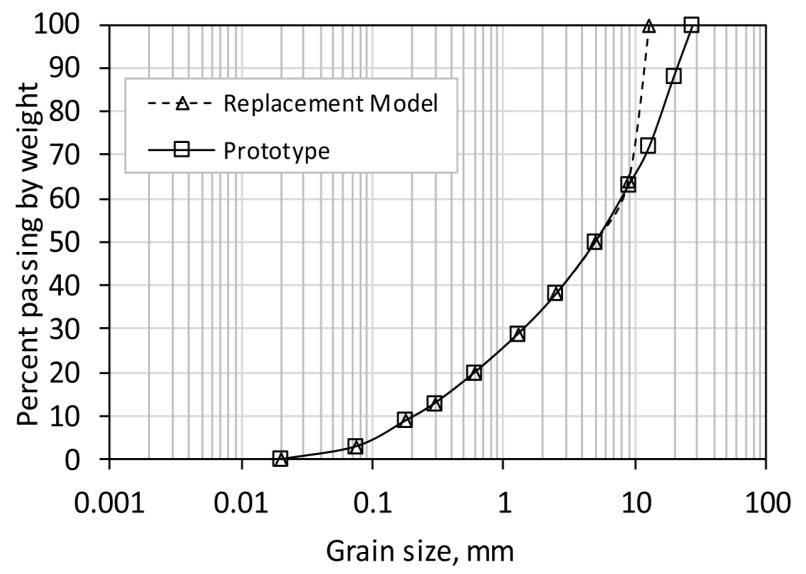

b)

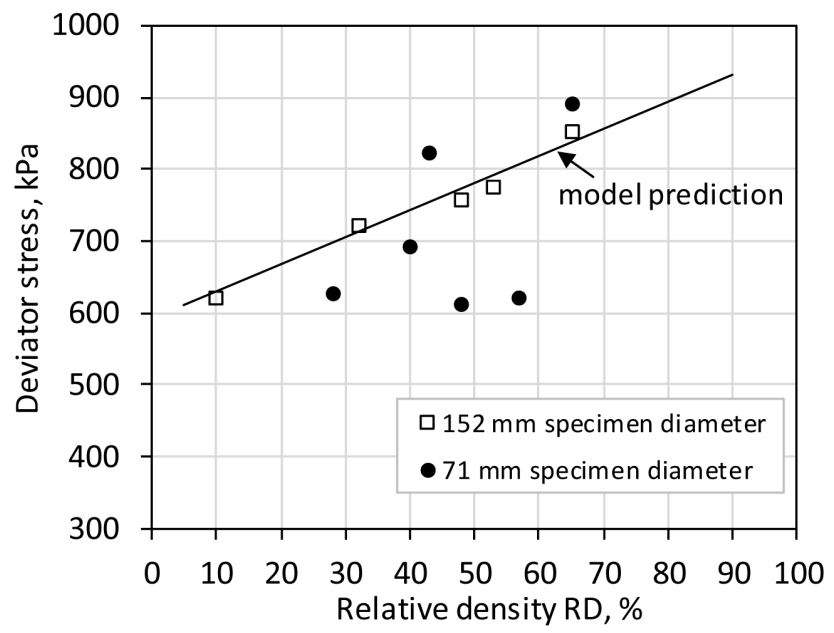

Figure 13: a) PSDs tested and b) deviator stress versus relative density (Su, 1989) 


\section{Discussion on scalping techniques}

The major issue of considering a percentage of oversize in the scalping techniques is that the scalping depends on how the particle size distribution is. As presented in Figures 1a and $1 \mathrm{~b}$, a comparison of a uniform and well graded PSD indicates that under a same scalping percentage, the maximum particle size is reduced 16 times for the well graded PSD against twice for the uniform gradation. This example illustrates that the scalping cannot be expressed as a percentage of the total material only, but also in terms of how the PSD is. Another important issue is that large particles act as a reinforcement, specially when the difference of particle size between the matrix and oversize particles is increased.

Three scalping techniques have been discussed, focused on evaluating the geomechanical properties of CGM. It was found that the percentage of scalping cannot be used solely when employing the scalping method, and then, the ratio of scalping needs to be considered in the analysis. Thus, Figure 14 presents a graph of scalping percentage versus ratio of scalping based on results from different authors. Moreover, Figure 14 depicts two regions where scalping can be applied. As these regions are limited to low ratio of scalping $(r<8)$, it is recommended the use of large-scale shear tests (triaxial or direct shear tests), which is in line with geomechanical recommendations of soils with oversize's by Charles (1991), Parkin (1991) and Nicks et al. (2015). Some coarse granular materials that

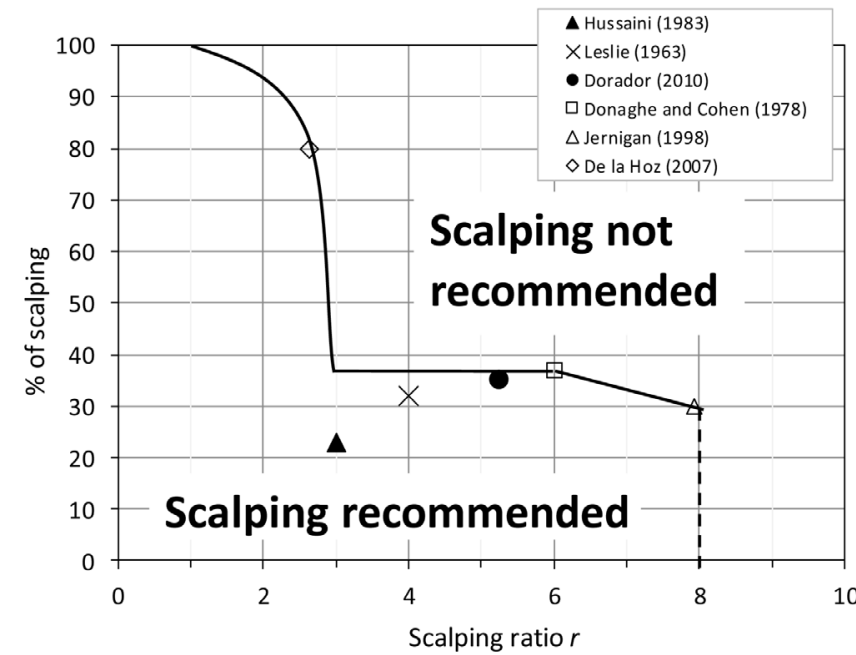

Figure 14: Experimental results of the variation of the scalping percentage with the scalping ratio and recommendation depending on scalping ratio and percentage of scalping can be characterized by the scalping method are rockfill materials, crushed stone for ballast materials, colluvium, alluvial and fluvial soils, waste rock dump and heap leach materials in mining.

\section{Conclusions}

The scalping techniques, i.e., scalping method, matrix method and scalping and replacement, were analyzed in detail in terms of its effectiveness, focusing on the mechanical properties of Coarse Granular Materials (CGM), with fines content lower than $10 \%$. Regarding the scalping techniques, the scalping method considers removing the oversized particles and using the remaining material for geotechnical characterization tests. The matrix method rests on the same idea of removing large particles, however, it focuses on soils in which the oversized particles are floating in a fine matrix. Finally, the scalping and replacement method, in addition to considering the removal of oversized particles, replaces the oversized fraction with an equal weight of material at a smaller size portion.

To conduct the analysis, it was necessary to define the ratio of scalping $r$, which is the ratio of maximum particle size of both prototype and scalped gradation. The analysis conducted in this paper indicated that these three methods are limited on its use, especially under small ratio of scalping. One of the reasons to explain this finding, is that as using any scalping technique, the scalped gradation will be finer, and then, the minimum and maximum density of the scalped gradation will be lower than the original gradation, being the material density a difficult parameter to define for testing.

It can be concluded that the percentage of scalping depends on the particle size distribution of the prototype gradation. Thus, a graph of percentage of scalping versus ratio of scalping is proposed. As the ratio of scalping is limited until 8 , it is recommended to conduct as large-scale shear tests as possible in order to apply the scalping method within the ranges of ratio of scalping and scalping percentage recommended. Scalping should consider variations of physical properties of CGM in size, such as shape, strength and roughness of particles. Further research is needed to evaluate the effectiveness of the scalping method in terms of others relevant properties of CGM such as cyclic shear strength, deformation modulus (static and dynamic) and permeability. 


\section{Acknowledgements}

The second author would like to acknowledge the funding provided by the academic activities fund FAA 01/2018 UCSC (Financiamiento de Actividades Académicas) from the Office of Research and Innovation (Dirección de Investigación e Innovación) at the Universidad Católica de la Santísima Concepción.

\section{References}

Al-Hussaini, M. (1983). Effect of particle size and strain conditions on the strength of crushed basalt. Canadian Geotechnical Journal 20(4), 706-717

ASTM D4718 (2015). Standard practice for correction of unit weight and water content for soils containing oversize particles. ASTM International, West Conshohocken, USA

ASTM D5030 (2013). Standard test methods for density of soil and rock in place by the water replacement method in a test pit. ASTM International, West Conshohocken, USA

Bard, E., Anabalón, M.E. and Campaña, J. (2012). Waste rock behavior at high pressures: dimensioning high waste rock dumps. In: Multiscale Geomechanics: From Soil to Engineering Projects, P.Y. Hicher (ed.), ISTE/Wiley, UK, chapter 4, 86-112

Bareither, C.A., Benson, C.H. and Edil, T.B. (2008). Comparison of shear strength of sand backfills measured in small-scale and large-scale direct shear tests. Canadian Geotechnical Journal 45(9), 1224-1236

Bolton, M.D., Fragaszy, R.J. and Lee, D.M. (1991). Broadening the specification of granular fills. Transportation Research Record 1309, 35-41

Charles, J.A. (1991). Laboratory shear strength tests and the stability of rockfill slopes. In Advances in Rockfill Structures, das Neves E.M. (ed.), NATO ASI Series (Series E: Applied Sciences), vol. 200. Springer, Dordrecht, 53-72

De la Hoz, K. (2007). Estimation of the shear strength parameters of coarse granular materials. MSc thesis, University of Chile, Santiago, Chile (in Spanish)

Donaghe, R.T. and Townsend, F.C. (1976). Scalping and replacement effects on the compaction characteristics of earthrock mixtures. Soil Specimen Preparation for Laboratory Testing, American Society for Testing and Materials ASTM, Philadelphia, USA, ASTM STP 599, 248-277
Donaghe, R.T. and Townsend, F.C. (1973). Compaction characteristics of earth-rock mixtures. Report 1, Vicksburg Silty Clay and DeGray Dam Clayey Sandy Gravel. Miscellaneous paper No. S-73-25, U.S. Army Engineer Waterways Experiment Station, Vicksburg, USA.

Donaghe, R.T. and Cohen, M.W. (1978). Strength and deformation properties of rock fill. Technical Report No. WES-TR-S-78-1. US Army Corps of Engineers, Waterways Experiment Station, Soils and Pavement Laboratory, Vicksburg, USA

Donaghe, R.T. and Torrey, V.H. (1985). Strength and deformation properties of earth-rock mixtures. Technical Report GL-859, Geotechnical Laboratory, US Army Corps of Engineers, Waterways Experiment Station, Vicksburg, USA

Donaghe, R.T. and Torrey, V.H. (1979). Scalping and replacement effects on strength parameters of earth-rock mixtures. $7^{\text {th }}$ European Conference on Soil Mechanics and Foundation Engineering: Design Parameters in Geotechnical Engineering, Brighton, UK, vol. 2, 29-34

Dorador, L. (2010). Experimental analysis of the methodologies of homothetic and shear curves in the geotechnical property evaluation of coarse soils. MSc thesis, University of Chile, Santiago, Chile (in Spanish)

Dorador, L. (2018). A revision of the parallel particle size distribution methodology or homothetic curves applied to the geotechnical characterization of coarse granular materials. $X$ Chilean Geotechnical Conference, Valparaiso, Chile, paper ID1259 (in Spanish)

Dorador, L. and Villalobos, F.A. (2020). Analysis of the geomechanical characterization of coarse granular materials using the parallel gradation method. Obras y Proyectos 27, 5063

Dorador, L., De la Hoz K., Salazar F. and Urbina F. (2018). Considerations in the geotechnical characterization of coarse granular materials. X Chilean Geotechnical Conference, Valparaiso, Chile, paper ID1315 (in Spanish).

Flora, A. and Modoni, G. (1997). Upgrading equipment and procedures for stress path triaxial testing of coarse-grained materials. Geotechnical Testing Journal 20(4), 459-469

Fragaszy, R.J., Su, J., Siddiqi, F.H. and Ho, C.L. (1992). Modeling strength of sandy gravel. Journal of Geotechnical Engineering 118(6), 920-935 
Fragaszy, R.J., Su, W. and Siddiqi, F.H. (1990). Effects of oversize particles on the density of clean granular soils. Geotechnical Testing Journal 13(2), 106-114

Hawley, M. and Cunning, J. (2017). Introduction. In Guidelines for Mine Waste Dump and Stockpile Design. Hawley, M. and Cunning, J. (eds.), CSIRO Publishing, Australia, 1-12

Jernigan, R.L. (1998). The physical modeling of soils containing oversized particles. $\mathrm{PhD}$ thesis, University of Colorado at Boulder, USA

Lambe, T.W. and Whitman, R.V. (1979). Soil mechanics. SI version. John Wiley \& Sons, New York, USA

Leslie, D.D. (1963). Large scale triaxial tests on gravelly soils. Second PanAmerican Conference on Soil Mechanics and Foundation Engineering, Brazil, vol. 1, 181-202

McCarter, M.K. (ed.) (1985). Design of non-impounding mine waste dumps. Society of Mining Engineering and the American Institute of Mining, Metallurgical and Petroleum Engineers, New York, USA

McLemore, V.T., Fakhimi, A., van Zyl, D., Ayakwah, G.F., Anim, K., Boakye, K., Ennin, F., Felli, P., Fredlund, D., Gutierrez, L.A.F., Nunoo, S., Tachie-Menson, S. and Viterbo, V.C. (2009). Literature review of other rock piles: characterization, weathering, and stability. Questa Rock Pile Weathering Stability Project. New Mexico Bureau of Geology and Mineral Resources. New Mexico Tech, USA

Nicks, J.E., Gebrenegus, T. and Adams, M.T. (2015). Strength characterization of open-graded aggregates for structural backfills. Publication No. FHWA-HRT-15-034. US Department of Transportation, Federal Highway Administration, USA
Ovalle, C., Linero, S., Dano, C., Bard, E., Hicher, P.Y. and Osses, R. (2020). Data compilation from large drained compression triaxial tests on coarse crushable rockfill materials. Journal of Geotechnical and Geoenvironmental Engineering 146(9), 06020013

Parkin, A.K. (1991). Rockfill modelling. In Advances in Rockfill Structures, das Neves E.M. (ed.), NATO ASI Series (Series E: Applied Sciences), vol. 200. Springer, Dordrecht, 35-51

Seif El Dine, B., Dupla, J.C., Frank, R., Canou, J. and Kazan, Y. (2010). Mechanical characterization of matrix coarse-grained soils with a large-size triaxial device. Canadian Geotechnical Journal 47(4), 425-438

Siddiqi, F.H. (1984). Strength evaluation of cohesionless soils with oversize particles. $\mathrm{PhD}$ thesis, University of California Davis, USA

Simoni, A. and Houlsby, G.T. (2006). The direct shear strength and dilatancy of sand-gravel mixtures. Geotechnical and Geological Engineering 24(3), 523-549

$\mathrm{Su}, \mathrm{W}$. (1989). Static strength evaluation of cohesionless soils with oversize particles. $\mathrm{PhD}$ thesis, Washington State University, USA

Valenzuela, L., Bard, E., Campaña, J. and Anabalón, M.E. (2008). High waste rock dumps - Challenges and developments.

First International Seminar on the Management of Rock Dumps, Perth, Australia, 65-78.

Zeller, J. and Wullimann, R. (1957). The shear strength of the shell materials for the Göschenenalp Dam, Switzerland. $4^{\text {th }}$ International Conference on Soil Mechanics and Foundation Engineering, London, UK, vol. 2, 399-415 